\title{
The air crescent sign of invasive pulmonary aspergillosis in acute leukaemia
}

\author{
ML SLEVIN, GK KNOWLES, MJ PHILLIPS, AG STANSFELD, TA LISTER
}

From the Imperial Cancer Research Fund Department of Medical Oncology, and the Departments of Histopathology and Chest Medicine, St Bartholomew's Hospital, London

The radiographic appearance of an air crescent surrounding a dense opacity is classically associated with pulmonary aspergilloma in patients with pre-existing lung disease such as healed tuberculous cavities. ${ }^{1}$ We describe three patients with previously normal chest radiographs who developed air crescents as a manifestation of invasive pulmonary aspergillosis complicating acute leukaemia. In a further patient, who died of disseminated aspergillosis, an appearance mimicking pulmonary aspergilloma was found at necropsy. To our knowledge only 12 similar cases have been reported, ${ }^{2-5}$ and in none was tomography performed to aid diagnosis.

\section{Case reports}

Four patients with acute leukaemia developed invasive pulmonary aspergillosis during remission-induction chemotherapy (table). Each patient had had a normal chest radiograph before receiving cytotoxic chemotherapy. All four patients developed localised homogeneous shadowing on their chest radiographs while neutropenic.

Broad-spectrum antibiotic treatment was started but the radiographic changes progressed, and in three patients single or multiple air crescents appeared within the pulmonary shadowing during the following three weeks (fig). In one patient (case 4) tomography showed air crescent formation before the sign became apparent on plain radiography one week later.

One patient (case 1) failed to achieve remission of leukaemia, and died before the cause of the pulmonary shadowing could be established. No antifungal treatment was given to this patient. At necropsy both upper lobes

Address for reprint requests: Dr ML Slevin, ICRF Department of Medical Oncology, St Bartholomew's Hospital, West Smithfield, London EC1Z 7BE.

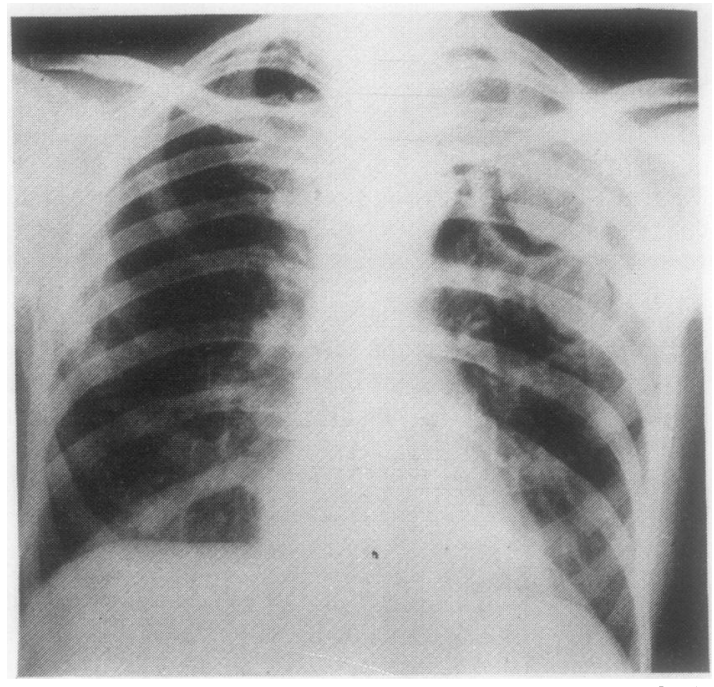

Figure Chest radiograph (case 2) showing cavities with air crescents in left lung.

showed multiple, thick-walled cavities containing a central sphere with surrounding air space. Histological examination of the cavity wall and central sphere showed infarcted lung tissue, heavily infiltrated with fungal hyphae, which were identified on culture as Aspergillus fumigatus. In the remaining patients bone marrow aspirates showed haematological remission, and all three recovered from their infection with gradual resolution of the lung shadowing. Two patients (cases 2 and 3 ) received the antifungal agent ketoconazole $(200 \mathrm{mg} /$ day $)$ for one year and 14

Findings and outcome in patients with acute leukaemia and invasive pulmonary aspergillosis

\begin{tabular}{|c|c|c|c|c|c|c|c|c|c|c|}
\hline \multirow[t]{2}{*}{ Patient No } & \multirow[t]{2}{*}{ Diagnosis } & \multirow[t]{2}{*}{ Age } & \multirow[t]{2}{*}{ Sex } & \multicolumn{3}{|c|}{ Cultures for Aspergillus } & \multicolumn{2}{|c|}{ Air crescents } & \multicolumn{2}{|l|}{ Lung } \\
\hline & & & & $\begin{array}{l}\text { Sputum } \\
\text { TTA }\end{array}$ & Blood & $F O B$ & $\begin{array}{l}\text { Chest } \\
\text { radiograph }\end{array}$ & Necropsy & Histology & $\begin{array}{l}\text { Survival } \\
\text { (months) }\end{array}$ \\
\hline 1 & $\begin{array}{l}\text { Acute myelogenous } \\
\text { leukaemia }\end{array}$ & 46 & $\mathbf{F}$ & ND & - & ND & - & + & + & 1 \\
\hline 2 & $\begin{array}{l}\text { Acute myelogenous } \\
\text { leukaemia }\end{array}$ & 36 & $\mathbf{F}$ & + & - & + & + & + & + & 12 \\
\hline 3 & $\begin{array}{l}\text { Acute myelogenous } \\
\text { leukaemia }\end{array}$ & 73 & $\mathbf{M}$ & + & - & - & + & ND & $*$ & 18 \\
\hline 4 & $\begin{array}{l}\text { Acute lymphoblastic } \\
\text { leukaemia }\end{array}$ & 21 & $\mathbf{F}$ & + & - & + & + & - & - & 14 \\
\hline
\end{tabular}

TTA = transtracheal aspirate; FOB = fibreoptic bronchoscopy; ND = not done.

${ }^{*}$ Histological appearance of transbronchial lung biopsy specimen consistent with the wall of a fungal cavity although hyphae not definitely identified. 
months respectively, but a substantial clinical and haematological improvement had occurred in both patients before the drug was started. The former (case 2) relapsed with acute leukaemia at one year and died. Necropsy showed abnormalities similar to those seen in case 1 . Patient No 3 is still alive and in remission, with minimal residual shadowing on chest radiograph 18 months after invasive pulmonary aspergillosis was diagnosed. Patient No 4 received no antifungal treatment. Relapse of acute leukaemia occurred seven months later in this patient, by which time the chest radiograph had returned to normal. She died shortly afterwards of bronchopneumonia, and a careful search for Aspergillus in the lung at necropsy proved negative.

\section{Discussion}

We have described four patients with acute leukaemia complicated by invasive pulmonary aspergillosis, three of whom developed single or multiple air crescents on chest radiograph, the fourth showing the same condition at necropsy. Each patient had a normal chest radiograph before receiving cytotoxic chemotherapy. The formation of air crescents in such patients appears to be rare, and to our knowledge only 12 similar cases have been reported. ${ }^{2-5}$ The clinical course of the patients described suggests that the attainment of haematological remission may have been more relevant to their recovery than antifungal treatment.

The pathological appearances in two of the patients who came to necropsy (cases 1 and 2) showed a cavity enclosed by a thick wall consisting of infarcted lung heavily infiltrated with fungal hyphae and a histologically similar central mass. It has been suggested that these lesions arise as a result of fungal invasion of infarcted lung that later sequesters centrally, forming a surrounding airspace. ${ }^{3}$ Whether the pulmonary infarct results from the occlusion of pulmonary vessels by fungal elements is unknown. Certainly both of our patients who died showed vascular invasion by fungal hyphae at necropsy.

Although the lesions observed in our patients superficially resemble pulmonary aspergillomas, there are important differences between the two. Classical pulmonary aspergillomas develop slowly, and are due to colonisation of pre-existing lung cavities by Aspergillus species, which behave as saprophytes. There is no fungal invasion of surrounding lung. The wall of the cavity is thin, and consists of fibrous tissue lined by ciliated columnar metaplastic squamous epithelium. The central mass or "fungal ball" comprises a dense meshwork of intertwined mycelia that lacks a lung tissue component. This clinical and pathological picture clearly contrasts with the rapid development of air crescents and the histological findings noted in our own patients and in the similar cases previously described. ${ }^{2-5}$

Invasive pulmonary aspergillosis in patients with acute leukaemia is often difficult to diagnose, and usually requires lung biopsy, either transbronchially using the fibreoptic bronchoscope or as an open procedure. In all 12 previously described patients with acute leukaemia who developed air crescents and in the four patients described here Aspergillus species were the only causative organisms identified. Evidently therefore the presence of this sign allows the diagnosis of invasive pulmonary aspergillosis to be strongly suspected on the basis of a chest radiograph alone. Our experience suggests that tomography may be valuable in allowing earlier detection of air crescent formation, and this investigation should be considered as a means of facilitating the diagnosis of this potentially lethal infection.

We thank Mrs Joanna Barton for assisting in the preparation of this manuscript.

\section{References}

' Varkey B, Rose H. Pulmonary aspergilloma. Am J Med 1976;61:626-31.

${ }^{2}$ Burke PS, Coltman CA. Multiple pulmonary aspergillomas in acute leukaemia. Cancer 1971;28:1289-92.

${ }^{3}$ Curtis AM, Walker-Smith GJ, Ravin CE. Air crescent sign of invasive aspergillosis. Radiology 1979;133:17-21.

4 Przyjemski C, Mattii R. The formation of pulmonary mycetomata. Cancer 1980;46:1701-4.

5 Sinclair AJ, Rossof AH, Coltman CA. Recognition and successful management in pulmonary aspergillosis in leukaemia. Cancer 1978;42:2019-24. 